\title{
Motivational Design Techniques to Increase Adherence to a Telemonitoring Therapy A Study with Adolescent Pectus Patients
}

\author{
Robin De Croon \\ Department of Computer Science \\ $K U$ Leuven \\ Celestijnenlaan 200A, BE-3001 Leuven \\ robin.decroon@cs.kuleuven.be
}

\author{
Dries Oeyen \\ BeWell Innovations
}

Lievevrouwestraat 10, BE-2520 Ranst

dries.oeyen@bewellinnovations.com

\author{
Alemitu Mequanint Bezabih, Jonas Geuens \\ Department of Computer Science \\ $K U$ Leuven
}

Andreas Vesaliusstraat 13, BE-3000 Leuven

\{alem.bezabih\} \& \{jonas.geuens\}@kuleuven.be

\author{
Davina Wildemeersch \\ Department of Algology \\ Antwerp University Hospital \\ Wilrijkstraat 10, BE-2650 Edegem \\ davina.wildemeersch@uza.be
}

Katrien Verbert

Department of Computer Science

KU Leuven

Celestijnenlaan 200A, BE-3001 Leuve

katrien.verbert@cs.kuleuven.be

\author{
Vero Vanden Abeele \\ Department of Computer Science \\ KU Leuven
}

Andreas Vesaliusstraat 13, BE-3000 Leuven

vero.vandenabeele@kuleuven.be

\begin{abstract}
The most common surgery for pectus patients is associated with severe acute and persistent postoperative pain. It is, therefore, important that patients are adequately monitored after their surgery to prevent the chronification of pain. This paper provides a deeper understanding of young adolescents when they are asked to use a telemonitoring platform for their postoperative follow-up. Motivational design techniques, such as gamification mechanics, were integrated into 17 alternative designs and evaluated via a mixed-method approach with eight pectus patients and nine parents. The quantitative scoring of all 17 designs on a seven-point Likert scale showed that participants appreciated the designs and were motivated to adhere to their telemonitoring therapy when adequately supported by the platform. A thematic analysis of in-depth interviews conducted in the context of their homes confirmed that pectus patients had the will to be adherent, were invested in their own wellbeing, appreciated technical feedback, valued their privacy, and requested a professional platform to support them in their daily telemonitoring activities.
\end{abstract}

Index Terms-Motivational design techniques, pectus, healthcare informatics, gamification.

\section{INTRODUCTION}

Funnel chest, a condition with a sunken appearance of the sternum, or pectus excavatum, occurs in one out of 400-1000 live births and is the most common chest wall deformity with an $80 \%$ to $90 \%$ incidence rate [1]. Pigeon chest, a raised appearance of the sternum, or pectus carinatum, is the second most common anterior chest deformity (15\%) [2]. Since both patients with pectus excavatum and pectus carinatum require a similar follow-up, this paper will refer to both patient groups as pectus patients. Pectus patients may experience severe negative psychosocial effects and avoid activities

This work is part of the research project PANACEA Gaming Platform with project number HBC.2016.0177, which is financed by Flanders Innovation \& Entrepreneurship. that expose the chest. As the symptoms become visible during childhood, surgery is frequently performed on younger patients. Moreover, the surgery is most likely performed for aesthetic reasons rather than as a necessary correction due to compression of underlying organs.

The most common surgical technique (minimal invasive pectus repair), is associated with severe acute and persistent postoperative pain, despite having a reduced surgical stress response, lower blood loss, and smaller incisions [3]. It is therefore important that patients are adequately monitored [4], [5]. However, "[d]espite the increased scientific interest in pain management after pectus surgery [6], [7], the provision of adequate pain management and the necessary antiemetic and psychological treatments during the whole perioperative period remain a challenge for health care providers." [1] Both preoperative psychological screening and long-term postoperative patient follow-up are needed.

New advances in the domain of healthcare informatics, such as telemonitoring, allow for better biopsychosocial follow-up. Telemonitoring is defined in this paper as the usage of information technology for the tracking and monitoring of the physical well-being of patients, at a distance [8]. Although telemonitoring is highly automated, there are still actions that are left up to the patient. Typically, patients need to setup a Bluetooth connection, wear the sensor appropriately, and charge the batteries. A lack of adherence to telemonitoring actions is therefore well documented. For example, Eysenbach [9] states that there "is the observation that in any eHealth trial a substantial proportion of users drop out before completion and stop using the application. [...] for many eHealth trials, in particular those conducted on the Internet and in particular with self-help applications, high dropout rates may be a natural and typical feature." 
The Economist's Intelligence Unit [10] reported on drop-out rates of 144 mobile health companies: $67 \%$ of the users of fitness or mobile health apps who needed to enter data manually, stopped within six months. Surprisingly, in the case of automated data capturing, e.g., tracking via sensors, an even higher dropout was reported, namely 74\% [11].

To maximize the effect of telemonitoring, it is important that patients are motivated to adhere to their postoperative followup. Prior research suggests that the addition of motivational design techniques, such as gamification mechanics, can have a positive impact on health and well-being when it targets behavioral outcomes [12], [13]. Therefore, we researched how motivational design techniques can be added to a telemonitoring platform tailored to younger patients, but also used by their parents.

To the best of our knowledge, there has been no research that focuses on motivational design techniques applied to a telemonitoring platform for pectus patients, a patient group characterized by preoperative anxiety and low selfesteem [14]; neither on potential misalignments between pectus patients and their parents. In this study, we aimed to evaluate, in a quantitative and qualitative manner, how young pectus patients perceive motivational design techniques supporting telemonitoring actions. First, we aimed to understand which motivational design techniques are rated positively and which are perceived negatively. Secondly, we aimed to explore the underlying reasons young pectus patients provide to explain these ratings, in a qualitative manner. What are the reasons underlying positive or negative ratings? The broader goal of this research study is to inform researchers and developers of telemonitoring applications on which motivational design techniques can promote increased adherence to follow-up. Hence, this study provides implications for the design and application of motivational design techniques in telemonitoring platforms for young patients facing potential persistent postoperative pain.

\section{RELATED WORK}

In this section, we first describe three fields of motivational design. Second, we discuss enhanced recovery pathways that can be supported with telemonitoring. Finally, the potential of motivational design targeting young adolescents is discussed.

\section{A. Improving adherence with motivational design techniques}

The term motivational design techniques is used in this paper as an umbrella term for all strategies that aim to improve patients' adherence, which in turn is referred to as the capacity of a patient to abide by mutually agreed recommendations regarding daily monitoring [15], [16]. This study applied techniques from three major fields of motivational design: 1) gamification, 2) persuasive design, and 3) behavior change techniques.

1) Gamification: Perhaps, the best known motivational design techniques are the application of gamification mechanics. The most widely-used definition of gamification is "the use of game design elements in non-game contexts," as defined by Deterding [17] in 2011. Gamification harnesses the motivational affordances of gameful experiences to influence psychological outcomes and further behavioral outcomes [18] and already has multiple applications in the healthcare informatics domain [12].

Effective gamification is a combination of game design, behavioral economics, motivational psychology, and user experience and user interface design [19]. If implemented well, gamification can increase the motivation of user's trajectories [20], [21]. However, Hamari et al. [18] have shown that gamification is not a panacea. Different user groups and personality types necessitate different gamification mechanics [22]-[24]. Hence, there is a need for research with respect to which gamification mechanics are appropriate for specific personality types and patient groups [25]. Finally, it is less known how gamification can be used within a sensitive setting, e.g., where patients submit private health data to the hospital. Little research can be found on how and what principles to implement in such a context.

Multiple gamification frameworks have been proposed in the literature that enlist different suitable gamification mechanics. For example, the octalysis framework by Chou [26], the curated list of game mechanics by Mythily and Herger [27], Tondello et al. [28]'s gameful design elements, and Marczewski [29]'s 52 gamification mechanics. All frameworks have their strengths and weaknesses and there is much overlap between them. This paper will build on Marczewski's framework [29] as it provides the most fine-grained division between mechanics.

2) Persuasive design: The Persuasive System Design [30] assumes that technology can be designed to change attitudes or behaviors through persuasion and social influence [31]. The model contains 28 design principles grouped in four categories: 1) primary task support, e.g., setting tailored goals or supporting self-monitoring, 2) dialogue support, e.g., sending reminders or providing rewards, 3) social support, e.g., providing social norms or fostering competition, and 4) system credibility support. e.g., establishing authority or listing thirdparty endorsements.

Another approach to design motivational design techniques is based on Cialdini [32]'s six principles, i.e., authority, commitment, consensus, scarcity, reciprocity, and liking. In this paper, we focused on the subset made by Kaptein et al. [33] who showed that persuasion profiles can be effective using implicit or explicit measures. Kaptein et al. [33] focused on the first four of the principles aforementioned and showed that "text messages that were personalized tailored - on the level of influence strategy susceptibility were more effective." [33] They did not only observe this effect at the behavioral level, but the personalized messages were also regarded as more useful by their participants. We will, therefore, built on their work to tailor telemonitoring reminders to the pectus patients.

3) Behavior change techniques: A third approach to inspire healthcare informatics researchers is Abraham 
and Michie's [34] taxonomy of behavior change techniques incorporating 26 techniques. Rather than clustering techniques in overarching categories, Abraham and Michie [34] link their motivational techniques to the underlying theoretical concepts of behavior change. For example, the design technique to provide rewards is related to Operant Conditioning [35], providing praise is related to self-efficacy in the Social Cognitive Theory [36].

\section{B. Enhanced recovery pathways and telemonitoring}

Enhanced recovery programs are used by the surgical team to help ensure patients have the best possible outcome from their surgery. Important components of these protocols occur before, during and after a procedure [37]. They have been implemented worldwide as evidence-based standardized perioperative approaches [38]. The use of electronic health technology [39], such as telemonitoring platforms, may facilitate biopsychosocial, postoperative follow-up, especially in the long term after hospital discharge [40].

Findings from the motivational design literature suggest that the inclusion and use of gamification may increase engagement [41], enjoyment [42], and improve the user experience [43] of these apps used in enhanced recovery programs. After all, these studies suggest a positive outcome with respect to a better uptake of a product or compliance to intervention.

\section{Young adolescents}

Studies on motivational design techniques targeting adolescents have already show potential. Waite-Jones et al. [44] conducted semi-structured focus groups and individual interviews with nine adolescents, eight parents and eight care providers. They found that an app for self-management should provide the adolescents with the ownership and control of an engaging tool that 1) gives information, 2) monitors symptoms, 3) offers reminders, and 4) provides social support. Furthermore, eight main themes were identified by Cai et al. [45] who involved 29 younger patients, seven parents, and 21 care providers from the rheumatology team. Their themes were: remote monitoring, treatment adherence, education and support, providing incentives, privacy, ease-of-use, clinical support tools, and attractiveness of the design.

Koivosto and Hamari have shown that there are important demographic differences in the perceived benefits from motivational design techniques and that the "ease of use of gamification is shown to decline with age." [46] However, this also indicates that there is an important potential for motivational design techniques targeting adolescents. Indeed, positive outcomes have been found with children [47], [48], adolescents [49], and young adults [50], [51].

\section{Methods}

\section{A. Study design and Appi@Home}

The full medical procedure, that contextualizes this study, is described in [1] and follows Werner and Kongsgaard's [52] working definition. Pectus patients were followed up by the multidisciplinary pain center for maladaptive coping strategies and pain-rehabilitation interference using their individual Appi@Home platform ${ }^{1}$, a web-based diary evaluating pain and sleep quality app. The patients were asked to use Appi@Home for 10 weeks after their discharge from the hospital. Their rehabilitation progress was monitored via Bluetooth-connected telemonitoring devices. Measurements were complemented with subjective personal diary answers, such as daily pain and activity assessments on an 11-level scale, which was also gathered through the Appi@Home app on patients' smartphones.

This study was performed during the ten week followup and employed a mixed-methods approach; a quantitative analysis of how young adolescents rated motivational design techniques and a qualitative analysis of interviews.

\section{B. Alternative design}

Based on the extensive literature on motivational design in healthcare informatics [53]-[55], two lead researchers, in close collaboration with medical experts from the multidisciplinary pain center and technical experts, designed a final set of 17 alternative designs. The goal of these 17 alternative designs was to span the largest spectrum of motivational design techniques possible that was acceptable by all the stakeholders in this sensitive context. Designs that focused on sharing medical data, for example, were unacceptable for the hospital. Neither did we want to introduce additional stress for the pectus patients, so designs focusing on a higher perceived threat [56] were also not included. Fig. 1 provides an overview of the chosen motivational designs, while Table I provides the rationale and underlying mechanics.

\section{In-depth interview}

After a minimum of two weeks post-surgery, the researcher visited the patient and parent(s) for a semi-structured indepth interview at their homes. This semi-structured, indepth interview was conducted according to the Contextual Inquiry method as defined by Beyer and Holtzblatt [59]. The contextual inquiry method is based on a combination of semistructured interviews and user observations and is based on four principles:

1) Context: the interviews and observations take place at the home of the pectus patient. Patients can easily show examples that they consider relevant in the discussion.

2) Partnership: the interviews are framed as a collaboration between the interviewer and the pectus patient (with their parent) during the activities or actions.

3) Interpretation: rather than a literal representation, the meaning is sought behind the words, shaping the behavior and perspective of the pectus patients.

4) Flexible focus: there is no a priori focus; during the interviews and observations, the focus can shift; above all available details, attention is paid to what is important for the research.

\footnotetext{
${ }^{1}$ APPI; Appi@Home, a European Union registered trademark under registration \#017610627
} 


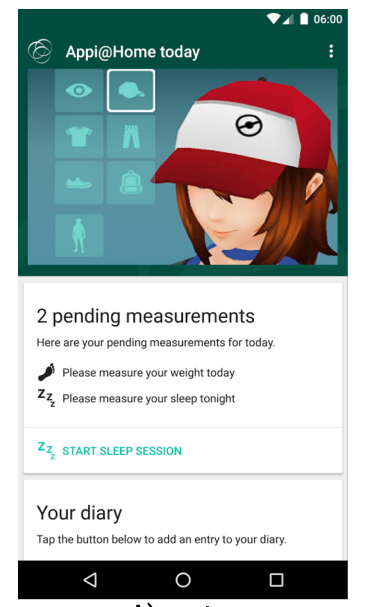

A) avatar

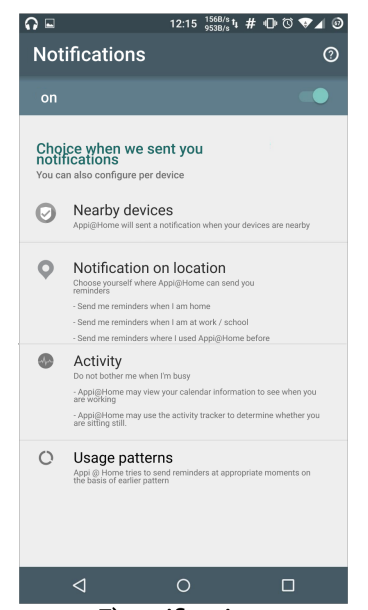

F) notifications
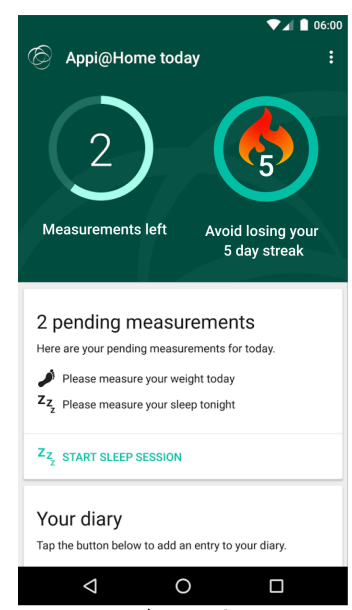

K) streak

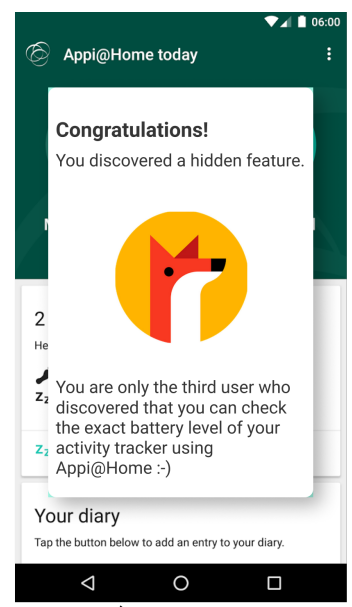

B) easter egg

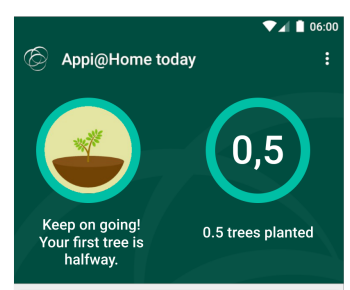

2 pending measurements

Here are your pending measurements for today.

f) Please measure your weight today

$z_{2}$ START SLEEP SESSION

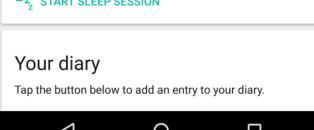

$\triangleleft \quad 0 \quad \square$

G) philanthropist
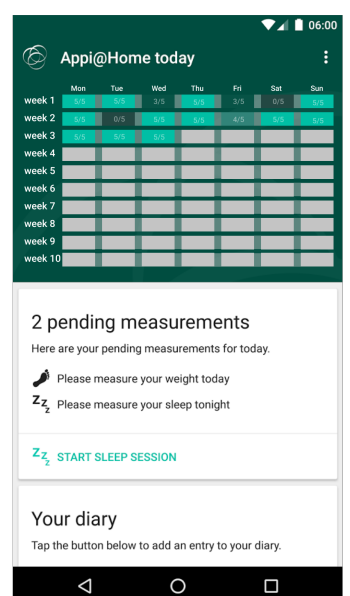

L) ten-week quest

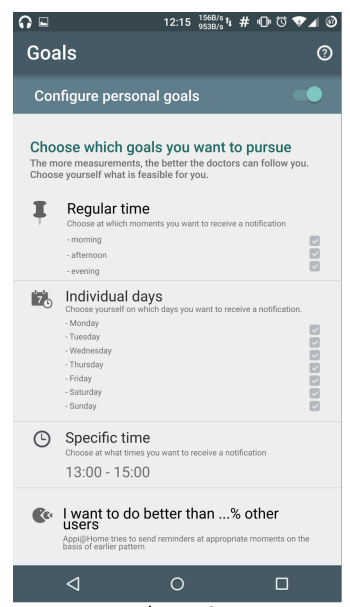

C) goals
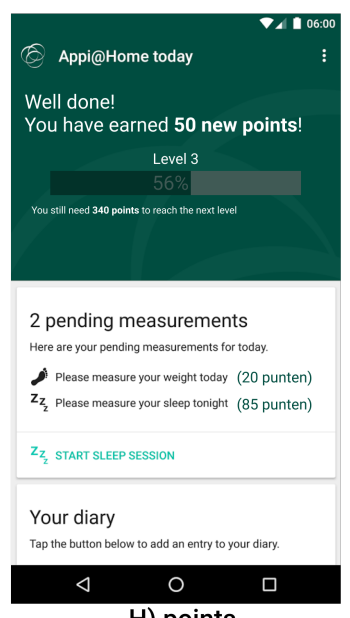

H) points
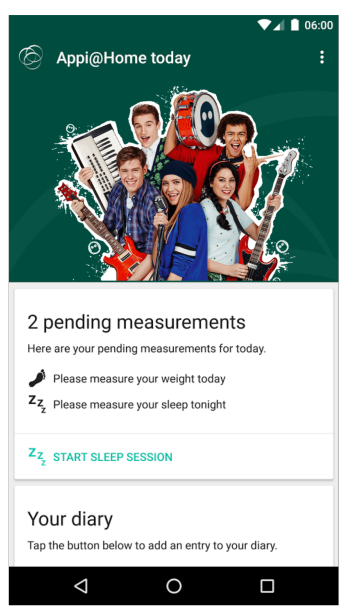

M) theme

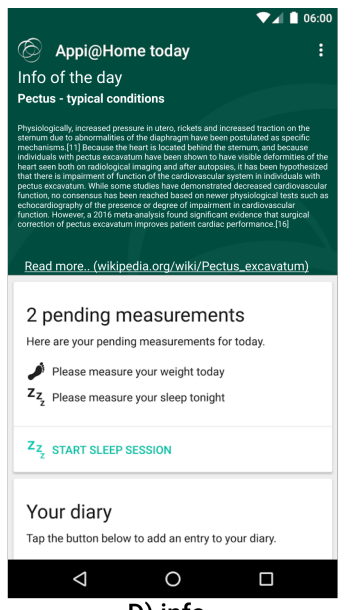

D) info

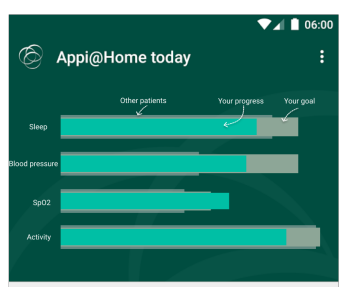

\section{2 pending measurements \\ Here are your pending measurements for today \\ D. Please measure your weight today \\ $z_{z}$ START SLEEP SESSION}

Your diary
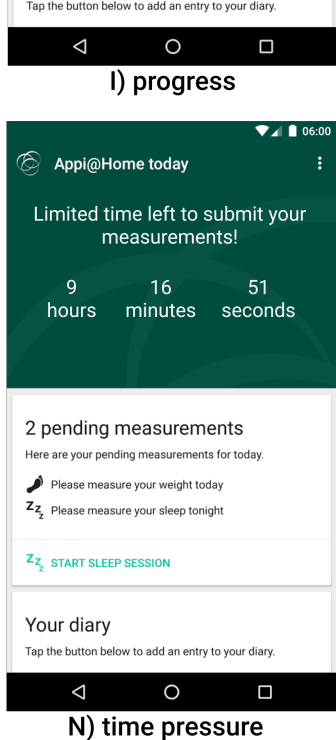

$\mathrm{N})$ time pressure

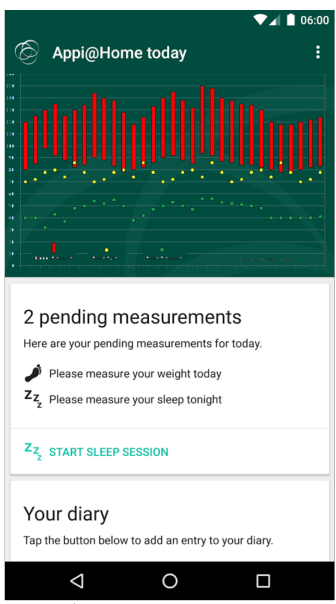

E) medical insights

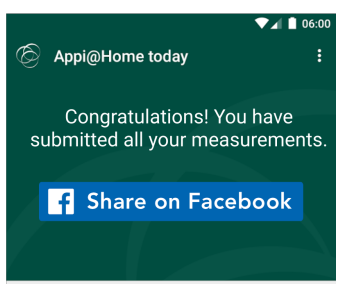

2 pending measurements

Here are your pending measurements for today

1) Please measure yur reight today

$z_{z}$ please measure your steep tonight

$z_{2}$ START SLEEP SESSION

Your diary

Tapthe button below to add an entry to your diary.
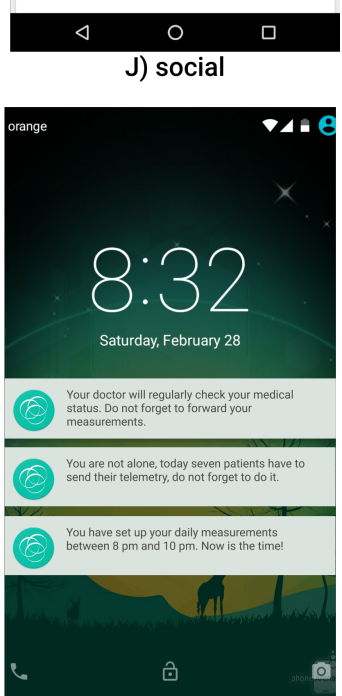

0) persuasive reminders

Fig. 1. Overview of all 17 designs that were rated by the pectus patients and their parents on a seven-point Likert scale. In this figure, the three motivational notifications were grouped in the last design $(\mathrm{O})$ for illustration purposes: the authority, consensus, and commitment notification. Participants, however, were shown the individual designs. 
TABLE I

THIS FINAL SET OF 17 DESIGNS WAS CAREFULLY SELECTED WITH TWO LEAD RESEARCHERS IN COLLABORATION WITH ALL STAKEHOLDERS. THE GOAL WAS TO SPAN THE LARGEST SPECTRUM OF MOTIVATIONAL DESIGN TECHNIQUES THAT WAS ACCEPTABLE IN THIS SENSITIVE CONTEXT.

\begin{tabular}{|c|c|c|c|}
\hline Design & Fig. 1 & Mechanic & Rationale \\
\hline Avatar & A & avatar & $\begin{array}{l}\text { This design shows an avatar on the main screen. Similar to earning points, patients can unlock new styles } \\
\text { for their avatar by submitting telemonitoring data. }\end{array}$ \\
\hline Consensus & $\mathrm{O}$ & $\begin{array}{l}\text { persuasion, } \\
\text { reminder }\end{array}$ & $\begin{array}{l}\text { This notification shows a motivational message based on Kaptein et al.'s [33] consensus profile. It } \\
\text { communicates that other pectus patients also need to submit their telemonitoring data. }\end{array}$ \\
\hline Goal & $\mathrm{C}$ & goal & $\begin{array}{l}\text { This configuration design empowers patients to choose their own goals. It enables patients to set specific } \\
\text { goals such as submitting telemonitoring data on a regular moment of day, individual days, specific time, } \\
\text { or even stimulates them to be more adherent than other pectus patients. }\end{array}$ \\
\hline Info & D & $\begin{array}{l}\text { random reward, } \\
\text { feedback }\end{array}$ & $\begin{array}{l}\text { Every day, new random related medical information is shown. Participants are triggered to open the app } \\
\text { every day to discover whether they are interested in the new information. }\end{array}$ \\
\hline Medical insights & $\mathrm{E}$ & $\begin{array}{l}\text { feedback, } \\
\text { progress }\end{array}$ & $\begin{array}{l}\text { This design enables patients to directly see the actual values of the telemonitoring data they submitted } \\
\text { inside the application itself. Furthermore, it also shows the progress made. }\end{array}$ \\
\hline Progress & I & $\begin{array}{l}\text { progress, } \\
\text { commitment, } \\
\text { competition }\end{array}$ & $\begin{array}{l}\text { Provides the patients with on overview of the total number of measurements submitted per device. The } \\
\text { grey bars in the background are used to visualize progress towards a goal and potentially the average } \\
\text { number of measurements performed by peers. }\end{array}$ \\
\hline Social & $\mathrm{J}$ & social & $\begin{array}{l}\text { This design allows the patient to share their progress on social media. It aims to facility support from } \\
\text { peers and friends. }\end{array}$ \\
\hline Streak & K & $\begin{array}{l}\text { loss aversion, } \\
\text { progress }\end{array}$ & $\begin{array}{l}\text { This design shows the total consecutive days a patient has submitted telemonitoring data and motives } \\
\text { patients to uphold their streak of compliant days. }\end{array}$ \\
\hline Ten-week quest & $\mathrm{L}$ & progress & $\begin{array}{l}\text { This design shows the total number of days telemonitoring data should be submitted. Each row is a new } \\
\text { week and each column a different day. Past days are colored based on the total number of telemonitoring } \\
\text { data submitted. This design allows patients to check both their progress and their adherence. }\end{array}$ \\
\hline Theme & $\mathrm{M}$ & theme, rewards & $\begin{array}{l}\text { Similar to Stinson et al. [58]'s Pain Squad research, patients can unlock exclusive videos within a theme } \\
\text { preferred by the patients. }\end{array}$ \\
\hline
\end{tabular}

To conduct the in-depth interview in a familiar environment, the main researcher visited each pectus patient at his/her home. These individual interviews were semi-structured according to a soft UX laddering [60] approach. Both pectus patients and their parents were asked to independently put each design that was printed on paper on a corresponding seven-point Likert score between - - - and +++ as shown in Fig. 2. By scoring each design, participants could signify their like or dislike of a motivational design technique. Care was given to avoid any influence of the parents on the pectus patients' rating, each of them first scored the motivational techniques without seeing the scoring of the other.

After the scoring, participants were invited to further comment on why they gave this scoring. The interviewer performed a semi-structured interview with the pectus patients and their parents for additional comments and whether they would like to add anything. After this, the interviewer thanked the participants for their efforts. Interviews ranged between 32 and 61 minutes, with an average of 45 minutes.

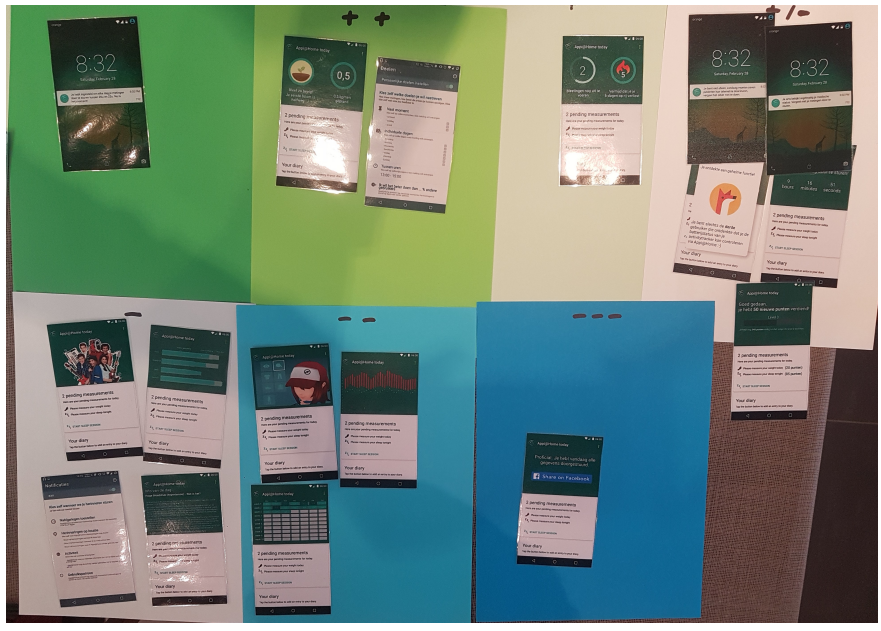

Fig. 2. Participants were asked to score each design on a seven-point Likert scale represented by colored sheets of paper. Dark green represented the most positive +++ designs, while dark blue the most negative - - -. Similar pictures were taken off all participants' ratings. 
TABLE II

DEMOGRAPHICS OF THE PATIENTS, GENDER, AGE, AND WHETHER THEIR PARENTS WERE PRESENT. EACH PATIENT, MOTHER, AND FATHER IS LABELED AS PX, MX, AND FX. RESPECTIVELY.

\begin{tabular}{|c|c|c|c|}
\hline Participant & Gender & Age & Parents \\
\hline P1 & Female & 13 & M1 + F1 \\
\hline P2 & Male & 18 & M2 \\
\hline P3 & Male & 15 & $/$ \\
\hline P4 & Male & 14 & M4 \\
\hline P5 & Male & 15 & M5 \\
\hline P6 & Male & 17 & F6 \\
\hline P7 & Male & 16 & M7 + F7 \\
\hline P8 & Male & 14 & M8 \\
\hline
\end{tabular}

\section{Participants}

All patients who underwent pectus surgery after February 2018 at the University Hospital of Antwerp (UZA), where informed about the study. Participants were informed and recruited prior to their surgery by medical professionals of the multidisciplinary pain center. Ethical approval for this study was granted by the hospital's ethics committee with number $17 / 08 / 082$. Information was provided about the intent of the study and patients were asked to sign a consent form detailing the collection, processing and storing of data, photos, and audio recordings collected during the study. Patients could stop their participation at any time.

Important to note is that these pectus patients are burdened with an above-average pain experience. That is why we worked closely with the medical professionals at the multidisciplinary pain center. The suitability of participants in this study was determined on the basis of consultation with the relevant physicians of the multidisciplinary pain center of UZA. Inclusion criteria were:

1) patients have been treated for a pectus condition,

2) patients use the Appi@Home telemonitoring platform,

3) patients should be able to fully understand his or her participation and be at least 13 years old. In case of legal minority, consent of a legal guardian is also required.

Over the course of one year, 13 patients were recruited. However, due to both personal and medical reasons five patients dropped out. Hence, eight pectus patients, aged 13-18 years $(\mathrm{M}=15.3, \mathrm{SD}=1.7)$ completed the study. As pectus excavatum affects four times more males than females [1] and pectus carinatum has an even more pronounced male predominance [2], we only had one female participant. In all but one interview, there was always a parent present. Two interviews had two parents present as shown in Table II.

\section{E. Data collection and analysis}

The researchers of this study had no access to the medical data, nor the medical patient file. During the interviews with the pectus patients, no medical information was shared, nor were medical aspects discussed. Only demographic data, such as gender, birth year and address were inquired.

The results (notes of the interview, possible audio recordings, transcripts of audio recordings and any photos) were stored in a university database managed by the principal researcher. Only the researchers involved in this project had access to these data during the course of the project.

The qualitative data was entered and coded into a spreadsheet for qualitative coding. During a first coding round, two researchers independently conducted a thematic analysis of eight interviews, according to the procedure described by Boyatzis [61].

This coding round resulted in the creation of a coding dictionary. One additional coding round was conducted to improve the coding dictionary and derive the thematic groupings of the motivational design techniques. A final coding round was conducted by two principal researchers (DC and $\mathrm{MB}$ ) to unearth the underlying central concept and derive the implications for design.

\section{RESUlts}

In this section, we first report on the quantitative rating by both the patients and their parents. Second, we discuss the results of a thematic analysis of all the interview transcripts. Quotes were translated by the main researcher and labeled as Px, Mx, and Fx for patient, mother, and father respectively.

\section{A. Likert scores}

As illustrated in Fig. 3, both patients and parents perceived most designs favorably. In order to prioritize the designs, we define positive in this paper by a median score $\geq$ ' + '. Within this definition, patients scored at least eight designs positive: the two configuration designs notifications and goals, two persuasive messages authority and commitment, and the philanthropist, streak, time pressure, and progress designs.

As shown in Fig. 3, parents often had a different opinion. Parents scored 12 designs positive: avatar, commitment, consensus, easter egg, info, medical insights, points, tenweek quest, theme, progress, philanthropist, and streak.

Interestingly, there was thus only an agreement between the patients and the parents with regards to four designs: philanthropist, streak, commitment, and progress.

The overall best-perceived design was the philanthropist design in which patients contribute to a good cause by consistently submitting their telemetry data.

P6: "The more [measurements] you do, the more plants, that is also a great idea!"

P4: "I really like that, I really like that tree, that you would plant a tree, because then you still do something good for the world"

P7: "Trees, yes, because I think that can stimulate people in a way."

Parents rated this philanthropist design as the best design. All parents gave it a positive score, resulting in a median score of '+ +'. "What does it cost you? Five minutes to do the measurement, and you keep a tree alive!" (F1). However, both patients and parents were skeptic and wanted verification that their contribution was carried out.

P1: "Yeah, I just don't know. Are you really going to plant a tree?" 


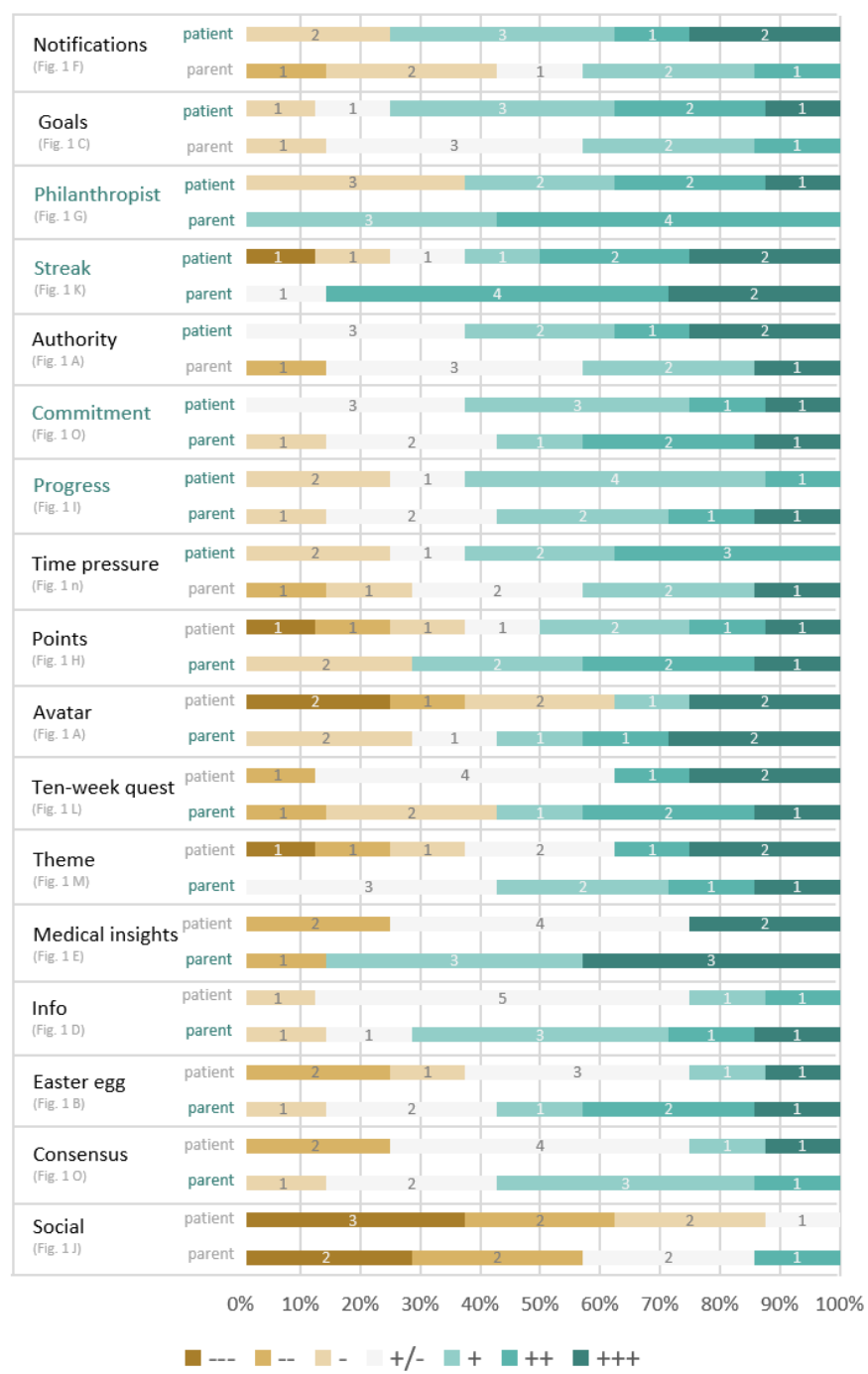

Fig. 3. $100 \%$ bar chart visualizing how patients and their parents scored all 17 designs on a seven-point Likert scale. Sorted by patients' preference. When a group rated a design positive (median $\geq$ '+') it is colored green. If a design was rated positive by both patients and parents, the name of the designs is also displayed in green.

P8: "Is this really the case? That this is a goal that actually will be carried out?"

M2: "But then you should also see that something has happened with it afterward."

The second design that was perceived well by both groups was the streak design. Most patients and almost all parents (M2 did not understand it initially) perceived the design to be useful. Many patients made the link with the popular multimedia messaging app Snapchat. "That with the flames, yes that's something useful! You really want to avoid losing five days in a row, that's like Snapchat, right. You do not want to lose that, so you always get more and more, yes that's something cool." (P2) Patients were even saying it would motivate them to constantly take all telemonitoring devices with them (P5). Patients indicated that the streak design could help them to verify their adherence: "that's nice to know, of course, to know how many days you have done in a row." (P4)

Parents also recognized the will of their children to keep their streak going: "yes, in the end, it works like that with those streaks. That those young guys, oh I have to do my streaks, yeah that works. Or, like if I have not done it, then I am back to zero." (M4)

The commitment design was the third preferred design. Remark that there is a clear difference between the rating of the authority and commitment designs, which were perceived rather positive, and the consensus design which scored lower. However, most participants indicated their rating was primarily guided by the need for reminders, not so much the actual persuasive messages. The designs might have scored higher "simply because they are notifications. I missed that." (P6) "I just put all three on the plus, because I did not really read which messages they were, I just have visual: it's notifications, short messages, I would like that." (F6)

The progress design was the final design perceived positive by both groups. This design integrates multiple motivational design techniques into one design, which is also reflected by the participants, who favor the competitive part, the feedback towards their own goal, and/or the visual progress.

P2: "To see that I have already done this, and others have not done this yet, that is also something competitive [...] that shows that you are doing a good job and that other people are not. Yes, something competitive [...] then I would like to do a bit more effort."

P3: "I think that's good too, because you know that, I have done so many measurements of that or that, which do I do the most, which the least?"

P5: "This also adds a little pressure and yes, such a goal, I think I had to do it just about every day, so yes [...] eh, yes, maybe this is useful, so to say, now I've done too little this week."

Although they did not qualify as positive by the parents, the designs with the highest perceived value by the patients were the configuration designs notifications and goals, mainly thanks to the ability to receive and configure notifications.

P4: "I think that reminder on location is easy, that you come home so that you get a message after a quarter of an hour or so, after you have put away your bag, taken your coat off, changed clothes."

P5: "it seems convenient that you say that time I am still awake anyway. I know that I then normally always use it, so I would like a reminder."

Finally, the biggest difference between the patients and the parents surfaced with the avatar and theme designs. Parents recognized the principle of using and customizing an avatar from other games they saw their children playing, therefore thinking their children would also like this feature in Appi@Home. On the other hand, patients, in general, did not like the avatar design, calling it too childish (P2, P6, P7, P8) or too gamified. The app's main purpose was to submit patients' telemetry data (P1, P2, P3, P5, P8). It should not be a 
game. Similar remarks were made for the theme design, with an emphasis on it being too childish (P2, P3, P4, P5, P6, P8).

\section{B. Thematic analysis}

All interviews were coded twice for emergent themes in an open-coding round by one researcher to establish a coding dictionary. During this initial coding session, codes from previously coded interviews were constantly compared to new interviews. After coding these eight interviews, an additional researcher re-coded all interviews again to improved the coding tree. Based on the results of these coding rounds, a consensus could be established for the coding dictionary. The following five themes remained: 1) adherence, 2) medical insights, 3) technical support, 4) private life, and 5) meansto-an-end. However, themes might overlap. For example, technical support might help to increase adherence, which in turn might lead to more useful medical insights.

1) Adherence: Most participants indicated they had the will to adhere to their postoperative telemonitoring therapy. This made adherence the most frequently occurring theme.

P4: "I actually find this a little [***], because you say I'm going to do that every day, then you should not say, oh, my parents are divorced, so I can not do that, You can put all the devices in your bag and take it with you."

P6: "That's nice that you can see ah oops, I forgot that day, I'm going to have to make up for it."

M1: "I think that is very important, yes important, it would be useful to have a quick overview, how far in the process are we and how often do you do it, are you doing well, or are you doing it less well, I think that is important."

The will to be adherent was frequently addressed when discussing all designs related to reminders and notifications. Participants indicated they wanted to adhere, but with the best intentions, they sometimes just forgot. Participants explicitly indicated they were committed. "If you say you do something, you do that." (P4) and "I would like more reminders, so you do not forget." (P6)

Parents had similar remarks and even trusted their children to adhere without reminders: "For me, that is actually no added value, he just does that every day, I trust that he does;" (M8) or "if it really would have helped, we would have set an alarm." (F7) Other parents were more controlling: "I go first, just before noon. Then I will check, and then the father. So two-time follow-up. We first let her do it, and then us." (M1) Parents argued that they let their child choose to participate or not, but when they agreed, they had to sit it through (F1, M4, M5, F7).

Although the ten-week quest design scored neutral, participants expressed it was "useful that you can see I have so many things to do and all yes, so many days to go." (P6). All participants indicated they did like to see the progress made so far. They also liked that it gave "a good overview when you have to bring it back, and how many days you have to do; and how much you have already done." (P1). However, this should just be an option, not the first thing you see when you open the platform.

Closely related to other motivation/adherence research [62], P7 also reported a decrease of interest over time: "In the beginning, I would look at this and then less and less."

2) Medical insight: The second most important theme was the need for more comprehensive medical insights. One of the main questions participants had, both patients and their parents, was whether they were doing OK, whether their values were within a healthy range.

The current mobile application only reported the meta data, i.e., only the number of measurements, but not the actual measurement values themselves. Although it was technically possible to see all measurements by logging in to the web client, participants were sometimes not aware of this functionality or found this too much effort. Furthermore, only the blood pressure and $\mathrm{SpO} 2$ sensor have an LCD that shows the values before transmission.

Three designs were praised by their ability to provide medical insights. Of course, the medical insight design is able to show the values and patterns directly. But also the authority reminder served as a confirmation the doctors were indeed checking the medical status. Participants (correctly) argued that everything is probably $\mathrm{OK}$, otherwise doctors would have informed them. Finally, the info of the day design was appreciated, if it would provide timely and relevant information on the progress of the healing process.

As is clear from the ratings for the medical insights design, as shown in Fig. 3, parents were more interested in the actual values than their children. "As parents, you want as much information as possible on those things." (F1) But they also inquired about the reliability of the devices: "Then I think like, how reliable are those things?" (M8) In contrast, patients indicated they did not know enough to care.

\section{P1: "Nice to see, how you progress, but for children, it is sometimes difficult, what does it mean?" P3: "No, this does not mean anything to me." P4: "I do not understand that."}

The info designs mainly scored neutral. Six patients (P1, P2, P3, P4, P5, P7) reported they did not like to read too much text. Patients argued that "if it is serious, then I will certainly hear it." (P8) Although the design should not be prominent, it definitely has its added value. It could inform users about what is to come and their path towards full recovery and in this manner provide patients with reassurance.

P3: "Now it is about blood pressure, but with me, they planted a rod inside my body, but then maybe what about the wound, did not get all the information from the doctor, but just nice text, maybe less text."

F7: "But before the operation, it would be much more interesting than after the operation, because you know what is going to come." 
P5: "So I did that once, no twice, went to the hospital because I had too much pain, so, if it would be added that now you could walk as many miles or something, or now you should already be able to start doing that, that would be useful, also because you then dare to do more than now."

3) Technical support: Related to will to be adherent, was the need to know whether all measurements were received and all technical devices were working well. Participants wanted to be aware of both technical issues, such as failing connections, or receive technical feedback, did the measurement arrive at the hospital?

The strengths of the progress, points, and ten-week quest designs, as perceived by the participants, were primarily the possibility to see their progress, but also to get immediate feedback whether all measurements were correctly received by the hospital.

P2: "Then you also see what the doctors see and possibly miss."

P5: "For example, the activity tracker, you can think, what is actually there, and then you realize ah yes, the battery might be empty."

M1: "Because I think it is important to know if it ends up with the doctors."

M8: "Except for when it does not come through, that I can ask you, have you already done that? That he says yes, that it has not been submitted or something."

This study also exposed some minor technical issues. However, these issues were related to specific situations and hardware and are already addressed with upcoming updates of the platform. Patients reported their will to adhere, but that this was sometimes hindered: "because when I fill it in, I immediately fill in everything - IF it works." (P2) Unfortunately, occasional connection issues might also have negatively influenced participants' confidence whether all measurements arrive at the hospital: "at least then I'm sure that message has arrived, right?" (P8)

4) Private life: Participants indicated that their surgery and postoperative telemonitoring follow-up belonged to their private life (M2). They indicated they had no interest in other patients: "yes I know that I am not alone, so it does not matter" (P1)

P3: "because I personally would not be interested in how many other people should do that, but other people might think differently about this."

As shown in Figure 3, the social design was, therefore, perceived as negative by the majority of participants.

P2: "I certainly would not use that, that share function, I think no one will use that, but I would not know. I would not want to share medical affairs on Facebook."

P5: "Not everyone should know that I have been treated in the hospital. Yes, many friends know, but to put this for everyone on Facebook... yeah, I do not like that, I do not think so, I also do not know if that complies with privacy regulations and so."

P8: "I would absolutely not want this."

However, in contrast, the progress and consensus design enabled participants to compare themselves with other patients in an anonymous manner. Four patients explicitly mentioned they liked this feature. These designs did not disclose any personal information, but only allowed participants to compare their relative performance to other similar patients.

P4: "I would add that, because when you do, you can continue to strive to be the best."

P6: "That too, but perhaps better than the best. That you can say so, I want to be the best. A kind of race." P2: "I have already done this, and others have not done that yet, that is also something competitive." P8: "Gives me a feeling of, yes I am among the best."

5) Means-to-an-end: The final theme is means-to-an-end. The goal of the telemonitoring platform is to support patients to submit telemonitoring data towards the hospital for further follow-up: "especially to me this is mainly about medical issues and I do not see that as a game." (P8)

Patients favored techniques that empowered them to control notifications and set their own goals. Designs that were too game-like such as the avatar and the theme scored lower. This may also explain the lower rating of the easter egg.

P5: "yeah, this is not the app where you go, keep on searching. So to say, you will not be using this app for your pleasure I think so; no, it's about those measurements, right?"

Finally, the time pressure design scored neutral. Participants expected they will be informed about the remaining time. This feature should just be present, but not necessarily on the home screen.

P6: "That is also useful that you know that I still have so much time to do that.

P8: "Then you really have a timer, then it is clearer how much time you have, because I do all my measurements on time, but suppose someone does that in the evening, suppose you have a busy day, then you will see clearly how time you have left.

\section{Discussion}

\section{A. Understanding pectus patients}

Overall, pectus patients perceived the integration of motivational design techniques as useful. Patients foremost expected a platform that always worked and supported them in their telemonitoring therapy. They welcomed motivational design techniques that showed them how they were doing, empowered them to set their own goals and reminders, and kept high standards towards the confidentiality of the data.

Patients articulated the intention to adhere to their telemonitoring therapy and certainly for a limited period of time, such as the ten weeks required after pectus surgery. Designs that support patients in showing their progress were 
perceived well. Similarly, patients appreciated designs that showed them how they were performing. Frequent questions asked were: did the hospital receive all data, did we forget a measurement, and can we do better? Reasons for the will to be adherent are threefold: 1) the main reason was to allow their care team to provide more adequate care; 2 ) once committed, they felt motivated to finish the follow-up period; and 3) they also indicated they were potentially helping future patients by providing their care team with more data.

The use of a telemonitoring platform may facilitate biopsychosocial, postoperative follow-up, especially in the long term after hospital discharge [40]. However, the captured data is currently mainly used by the professional care team. Parents often expressed that they would also appreciate additional insights on how their children are recovering. After all, unnecessarily avoiding activities to avoid pain, might have an adverse effect on the recovery [52], [63]. More medical insights might empower both patients and parents.

Young adolescents in this sample were particularly motivated by helping other people. The philanthropist design was perceived as one of the best designs. In close relation to McGonigal's [64] epic scale, patients felt they were part of something bigger, that their actions were contributing to something. Although this might be considered as shifting patients' motivation to an external motivator, patients cited this as an additional motivator. After all, their main interest was to recover. Moreover, not only charity motivated the adolescents, but also knowing that their data could help the care team to improve future treatment plans. One participant (P1) even recommended changing the theme design to videos of past patients. The fully recovered patients could provide motivational messages to future pectus patients, similar to the professional actors in Pain Squad [58].

Finally, in contrast to other related research [30], [44], we found that pectus patients and their parents strongly disliked direct social contact in their medical telemonitoring platform. This is in line with Geuens et al. [65] who also found that "every patient hurts in his own way." We subscribe to this finding: also young pectus patients consider health issues as private. The context should thus always be studied before integrating social features.

\section{B. Implications for design}

Gamified applications are perceived as 'gestalts' by their users, they are perceived as one meaningful whole, rather than a mere atomistic addition of gamification elements [66]. We want to postulate that it is less relevant to choose one specific design to embed in a telemonitoring application. The implementation of the points design, for example, can be framed from a behaviorist perspective (a reward), as well as from self-determination (promoting a sense of competence), or the trait perspective (promoting status) [67]. More important is to study how the various motivational design techniques are operationalized and perceived by its users in the design. In this study, for instance, pectus patients primarily valued the points design thanks to its ability to show progress, not because it could show competence or status.

We, therefore, do not argue to pick one or two designs to be integrated into a telemonitoring application targeting young adolescents, but argue to understand the motivation and incentives of the target group first. We also recommend to involve parents in the design process, as they are an important stakeholder in the healing process of the patient. Our results show that pectus patients were particularly motivated by helping other patients. Finally, we showed that a robust platform and a flawless user experience are an important prerequisite before integrating motivational design techniques into a telemonitoring application.

\section{Limitations and future work}

This study has a few limitations that affect the contribution. First, the sample sizes are too small for meaningful statistics. However, like Sonne et al. [68], we argue "that it is more important to first uncover potential problems and understand the use of the technology, than to conduct longer and larger efficacy studies." Furthermore, UZA is one of the five biggest hospitals in the country and is specialized in pectus surgery. All pectus patients were informed and invited.

Second, with this study, we cannot recommend one best design. Often motivational design techniques are considered modular elements, which are simply added to the application. This reflects an additive-deterministic notion of gamification [66]. According to such a simplistic reasoning follows then the more gamification, the better. In such studies, neither the quality of the gamification nor the coherence with other components is examined, nor how these elements can be operationalized for a specific user group or context.

Notwithstanding these limitations, we were able to provide a deeper understanding of pectus patients in the context of telemonitoring and demonstrate the perceived usefulness of alternative designs. Next, we will integrate these lessons learned in a new telemonitoring platform and scientifically monitor whether we can indeed impact patients' adherence.

\section{CONCLUSION}

In this paper, we provided a deeper understanding of young adolescents when they are asked to use a telemonitoring platform for their postoperative follow-up. In total, 17 alternative designs that integrated various motivational design techniques were carefully designed with all stakeholders.

A mixed methods study with eight pectus patients and nine parents revealed that adolescent pectus patients had the will to be adherent, were invested in their own wellbeing, appreciated technical feedback, valued their privacy, and requested a professional platform to support them in their daily telemonitoring activities.

Quantitative analysis revealed that patients perceived the configuration designs as very useful. Finally, pectus patients, and in general young adolescents, were particularly motivated by philanthropistic reasons. 


\section{REFERENCES}

[1] D. Wildemeersch, M. D'Hondt, L. Bernaerts, P. Mertens, V. Saldien, J. M. H. Hendriks, A.-S. Walcarius, L. Sterkens, and G. H. Hans, "Implementation of an enhanced recovery pathway for minimally invasive pectus surgery: A Population-Based cohort study evaluating short- and Long-Term outcomes using ehealth technology," JMIR Perioperative Medicine, vol. 1, no. 2, p. e10996, 2018.

[2] A. A. Fokin, N. M. Steuerwald, W. A. Ahrens, and K. E. Allen, "Anatomical, histologic, and genetic characteristics of congenital chest wall deformities," Semin. Thorac. Cardiovasc. Surg., vol. 21, no. 1, pp. 44-57, 2009.

[3] D. Nuss, R. E. Kelly, Jr, D. P. Croitoru, and M. E. Katz, "A 10-year review of a minimally invasive technique for the correction of pectus excavatum,” J. Pediatr. Surg., vol. 33, no. 4, pp. 545-552, Apr. 1998.

[4] A. D. Kristensen, T. A. L. Pedersen, V. E. Hjortdal, T. S. Jensen, and L. Nikolajsen, "Chronic pain in adults after thoracotomy in childhood or youth,” Br. J. Anaesth., vol. 104, no. 1, pp. 75-79, Jan. 2010.

[5] G. Williams, R. F. Howard, and C. Liossi, "Persistent postsurgical pain in children and young people: prediction, prevention, and management," Pain Rep, vol. 2, no. 5, p. e616, Sep. 2017.

[6] C. Graves, O. Idowu, S. Lee, B. Padilla, and S. Kim, "Intraoperative cryoanalgesia for managing pain after the nuss procedure," J. Pediatr. Surg., vol. 52, no. 6, pp. 920-924, Jun. 2017.

[7] A. M. Stroud, D. D. Tulanont, T. E. Coates, P. P. Goodney, and D. P. Croitoru, "Epidural analgesia versus intravenous patient-controlled analgesia following minimally invasive pectus excavatum repair: a systematic review and meta-analysis," J. Pediatr. Surg., vol. 49, no. 5, pp. 798-806, May 2014.

[8] G. Paré, M. Jaana, and C. Sicotte, "Systematic review of home telemonitoring for chronic diseases: the evidence base," J. Am. Med. Inform. Assoc., vol. 14, no. 3, pp. 269-277, May 2007.

[9] G. Eysenbach, "The law of attrition," J. Med. Internet Res., vol. 7, no. 1, p. e11, 31 Mar. 2005

[10] Economist Intelligence, "Power to the patient: How mobile technology is transforming healthcare," The Economist, Tech. Rep., 2015.

[11] PriceWaterHouseCooper Global Health Unit, "Emerging mhealth: Paths for growth," pwc, Tech. Rep., 2014.

[12] R. De Croon, D. Wildemeersch, J. Wille, K. Verbert, and V. Vanden Abeele, "Gamification and serious games in a healthcare informatics context," in Proceedings of the 2018 International Conference on Healthcare Informatics, 2018, pp. 1-11.

[13] D. Johnson, S. Deterding, K.-A. Kuhn, A. Staneva, S. Stoyanov, and L. Hides, "Gamification for health and wellbeing: A systematic review of the literature," Internet Interventions, vol. 6, pp. 89-106, 1 Nov. 2016.

[14] C. Steinmann, S. Krille, A. Mueller, P. Weber, B. Reingruber, and A. Martin, "Pectus excavatum and pectus carinatum patients suffer from lower quality of life and impaired body image: a control group comparison of psychological characteristics prior to surgical correction," Eur. J. Cardiothorac. Surg., vol. 40, no. 5, pp. 1138-1145, Nov. 2011.

[15] M. E. Inkster, P. T. Donnan, T. M. MacDonald, F. M. Sullivan, and T. Fahey, "Adherence to antihypertensive medication and association with patient and practice factors," J. Hum. Hypertens., vol. 20, no. 4, pp. 295-297, Apr. 2006.

[16] F. Sieverink, S. M. Kelders, and J. E. van Gemert-Pijnen, "Clarifying the concept of adherence to ehealth technology: Systematic review on when usage becomes adherence," J. Med. Internet Res., vol. 19, no. 12, p. e402, Dec. 2017.

[17] S. Deterding, D. Dixon, R. Khaled, and L. Nacke, "From game design elements to gamefulness: defining gamification," in Proceedings of the 15th international academic MindTrek conference: Envisioning future media environments. dl.acm.org, 2011, pp. 9-15.

[18] J. Hamari, J. Koivisto, and H. Sarsa, "Does gamification work? - a literature review of empirical studies on gamification," in 2014 47th Hawaii International Conference on System Sciences, Jan. 2014, pp. 3025-3034.

[19] Y.-K. Chou, Actionable gamification: Beyond points, badges, and leaderboards. Octalysis Group, 2016.

[20] B. De Schutter and V. Vanden Abeele, "Designing meaningful play within the psycho-social context of older adults," in Proceedings of the $3 r d$ International Conference on Fun and Games, ser. Fun and Games '10. New York, NY, USA: ACM, 2010, pp. 84-93.

[21] K. M. Kapp, The Gamification of Learning and Instruction: Game-based Methods and Strategies for Training and Education. John Wiley \& Sons, May 2012.
[22] C. Bateman, R. Lowenhaupt, and L. Nacke, "Player typology in theory and practice," in DiGRA Conference, 2011.

[23] R. Orji, R. L. Mandryk, J. Vassileva, and K. M. Gerling, "Tailoring persuasive health games to gamer type," in Proceedings of the SIGCHI Conference on Human Factors in Computing Systems, ser. CHI '13. New York, NY, USA: ACM, 2013, pp. 2467-2476.

[24] G. F. Tondello, R. R. Wehbe, L. Diamond, M. Busch, A. Marczewski, and L. E. Nacke, "The gamification user types hexad scale," in Proceedings of the 2016 Annual Symposium on Computer-Human Interaction in Play. ACM, Oct. 2016, pp. 229-243.

[25] R. De Croon, D. Wildemeersch, J. Wille, K. Verbert, and V. Vanden Abeele, "Anthropomorphism-Based focus group protocol to select gamification mechanics," in Proceedings of the Positive Gaming: Workshop on Gamification and Games for Wellbeing co-located with the ACM SIGCHI Annual Symposium on Computer-Human Interaction in Play (CHI PLAY 2017), 2017.

[26] Y.-K. Chou, "Octalysis: Complete gamification framework," Yu-Kai Chou \& Gamification, 2013.

[27] J. K. Mythily and M. Herger, "Chapter 6: Mechanics," https://www.interaction-design.org/literature/book/gamification-atwork-designing-engaging-business-software/chapter-6-58-mechanics, accessed: 2017-11-27.

[28] G. F. Tondello, A. Mora, and L. E. Nacke, "Elements of gameful design emerging from user preferences," in Proceedings of the Annual Symposium on Computer-Human Interaction in Play. ACM, Oct. 2017, pp. 129-142.

[29] A. C. Marczewski, "Gamification mechanics elements," https://www.gamified.uk/user-types/gamification-mechanics-elements, 2017, accessed: 2017-8-4.

[30] H. Oinas-Kukkonen and M. Harjumaa, "Persuasive systems design: Key issues, process model, and system features," Communications of the Association for Information Systems, vol. 24, no. 1, p. 28, 2009.

[31] B. J. Fogg, "Persuasive technology: using computers to change what we think and do," Ubiquity, vol. 2002, no. December, p. 5, Dec. 2002

[32] R. B. Cialdini, Influence: Science and practice. Pearson education Boston, 2009, vol. 4.

[33] M. Kaptein, P. Markopoulos, B. de Ruyter, and E. Aarts, "Personalizing persuasive technologies: Explicit and implicit personalization using persuasion profiles," International Journal of Human-Computer Studies, vol. 77 , pp. $38-51,2015$.

[34] C. Abraham and S. Michie, "A taxonomy of behavior change techniques used in interventions," Health Psychol., vol. 27, no. 3, pp. 379-387, May 2008.

[35] G. Martorella, M. Boitor, M. Berube, S. Fredericks, S. Le May, and C. Gélinas, "Tailored Web-Based interventions for pain: Systematic review and Meta-Analysis," J. Med. Internet Res., vol. 19, no. 11, p. e385, Nov. 2017.

[36] Q. A. Rahman, T. Janmohamed, M. Pirbaglou, P. Ritvo, J. M. Heffernan, H. Clarke, and J. Katz, "Patterns of user engagement with the mobile app, manage my pain: Results of a data mining investigation," JMIR Mhealth Uhealth, vol. 5, no. 7, p. e96, Jul. 2017.

[37] Department of Anesthesiology, UNC School of Medicine, "Basics of enhanced recovery I enhanced recovery program," https://www.med.unc.edu/anesthesiology/enhancedrecovery/overview/ components-of-enhanced-recovery/, 2019, accessed: 2019-2-5.

[38] H. Kehlet, T. S. Jensen, and C. J. Woolf, "Persistent postsurgical pain: risk factors and prevention," Lancet, vol. 367, no. 9522, pp. 1618-1625, May 2006.

[39] J. Ross, F. Stevenson, R. Lau, and E. Murray, "Exploring the challenges of implementing e-health: a protocol for an update of a systematic review of reviews," BMJ Open, vol. 5, no. 4, p. e006773, Apr. 2015.

[40] E. van der Meij, E. V. A. Bouwsma, B. van den Heuvel, H. J. Bonjer, J. R. Anema, and J. A. F. Huirne, "Using e-health in perioperative care: a survey study investigating shortcomings in current perioperative care and possible future solutions," BMC Surg., vol. 17, no. 1, p. 61, May 2017.

[41] J. Looyestyn, J. Kernot, K. Boshoff, J. Ryan, S. Edney, and C. Maher, "Does gamification increase engagement with online programs? A systematic review," PLoS One, vol. 12, no. 3, p. e0173403, 2017.

[42] Z. Fitz-Walter, D. Johnson, P. Wyeth, D. Tjondronegoro, and B. ScottParker, "Driven to drive? investigating the effect of gamification on learner driver behavior, perceived motivation and user experience," Comput. Human Behav., vol. 71, pp. 586-595, 2017. 
[43] L. Bodduluri, M. Y. Boon, M. Ryan, and S. J. Dain, "Impact of Gamification of Vision Tests on the User Experience," Games for Health Journal, vol. 6, no. 4, pp. 229-236, 2017.

[44] J. M. Waite-Jones, R. Majeed-Ariss, J. Smith, S. R. Stones, V. Van Rooyen, and V. Swallow, "Young people's, parents', and professionals' views on required components of mobile apps to support Self-Management of juvenile arthritis: Qualitative study," JMIR Mhealth Uhealth, vol. 6, no. 1, p. e25, Jan. 2018

[45] R. A. Cai, D. Beste, H. Chaplin, S. Varakliotis, L. Suffield, F. Josephs, D. Sen, L. R. Wedderburn, Y. Ioannou, S. Hailes, and D. Eleftheriou, "Developing and evaluating JIApp: Acceptability and usability of a smartphone app system to improve Self-Management in young people with juvenile idiopathic arthritis," JMIR Mhealth Uhealth, vol. 5, no. 8, p. e121, Aug. 2017

[46] J. Koivisto and J. Hamari, "Demographic differences in perceived benefits from gamification," Comput. Human Behav., vol. 35, pp. 179188, Jun. 2014.

[47] B. A. Jones, G. J. Madden, H. J. Wengreen, S. S. Aguilar, and E. A. Desjardins, "Gamification of dietary decision-making in an elementaryschool cafeteria," PLoS One, vol. 9, no. 4, p. e93872, 2014.

[48] A. Kadomura, K. Tsukada, and I. Siio, "Educatableware: sound emitting tableware for encouraging dietary education," Journal of Information Processing, vol. 22, no. 2, pp. 325-333, 2014.

[49] J. A. Cafazzo, M. Casselman, N. Hamming, D. K. Katzman, and M. R. Palmert, "Design of an mhealth app for the self-management of adolescent type 1 diabetes: a pilot study," Journal of medical Internet research, vol. 14, no. 3, 2012.

[50] I. Kuramoto, T. Ishibashi, K. Yamamoto, and Y. Tsujino, "Stand up, heroes!: gamification for standing people on crowded public transportation," in International Conference of Design, User Experience, and Usability. Springer, 2013, pp. 538-547.

[51] O. Zuckerman and A. Gal-Oz, "Deconstructing gamification: evaluating the effectiveness of continuous measurement, virtual rewards, and social comparison for promoting physical activity," Personal and ubiquitous computing, vol. 18, no. 7, pp. 1705-1719, 2014.

[52] M. U. Werner and U. E. Kongsgaard, "I. defining persistent post-surgical pain: is an update required?" $B r$. J. Anaesth., vol. 113, no. 1, pp. 1-4, Jul. 2014.

[53] M. Brown, N. O’Neill, H. van Woerden, P. Eslambolchilar, M. Jones, and A. John, "Gamification and Adherence to Web-Based Mental Health Interventions: A Systematic Review," JMIR Mental Health, vol. 3, no. 3 , p. e39, Aug. 2016.

[54] D. Johnson, S. Deterding, K.-A. Kuhn, A. Staneva, S. Stoyanov, and L. Hides, "Gamification for health and wellbeing: A systematic review of the literature," Internet Interventions, vol. 6, pp. 89-106, 2016.
[55] L. Sardi, A. Idri, and J. L. Fernández-Alemán, "A systematic review of gamification in e-Health," J. Biomed. Inform., vol. 71, pp. 31-48, 2017.

[56] I. M. Rosenstock, V. J. Strecher, and M. H. Becker, "Social learning theory and the health belief model," Health education quarterly, vol. 15, no. 2, pp. 175-183, 1988.

[57] Y.-K. Chou, "Actionable gamification," Beyond points, badges, and leaderboards, 2015.

[58] J. N. Stinson, L. A. Jibb, C. Nguyen, P. C. Nathan, A. M. Maloney, L. L. Dupuis, J. T. Gerstle, B. Alman, S. Hopyan, C. Strahlendorf, C. Portwine, D. L. Johnston, and M. Orr, "Development and testing of a multidimensional iphone pain assessment application for adolescents with cancer," J Med Internet Res, vol. 15, no. 3, p. e51, Mar 2013.

[59] H. Beyer and K. Holtzblatt, Contextual Design: Defining CustomerCentered Systems. Elsevier, Dec. 1997.

[60] V. Vanden Abeele and B. Zaman, "Laddering the user experience!" in User Experience Evaluation Methods in Product Development (UXEM'09)-Workshop, 2009.

[61] R. E. Boyatzis, Transforming Qualitative Information: Thematic Analysis and Code Development. SAGE, Apr. 1998.

[62] Z. Zhao, A. Arya, A. Whitehead, G. Chan, and S. A. Etemad, "Keeping users engaged through feature updates: A Long-Term study of using Wearable-Based exergames," in Proceedings of the 2017 CHI Conference on Human Factors in Computing Systems, ser. CHI '17. New York, NY, USA: ACM, May 2017, pp. 1053-1064.

[63] M. Matthews and G. Doherty, "In the mood: Engaging teenagers in psychotherapy using mobile phones," in Proceedings of the SIGCHI Conference on Human Factors in Computing Systems, ser. CHI '11. New York, NY, USA: ACM, 2011, pp. 2947-2956.

[64] J. McGonigal, Reality Is Broken: Why Games Make Us Better and How They Can Change the World. Penguin, Jan. 2011.

[65] J. Geuens, L. Geurts, T. W. Swinnen, R. Westhovens, and V. Vanden Abeele, "mhealth features supporting Self-Management behavior in patients with chronic arthritis: a Mixed-Method approach on patient preferences," JMIR mHealth and uHealth, Jan. 2019.

[66] S. Deterding, "Eudaimonic design, or: Six invitations to rethink gamification," in Rethinking Gamification, M. Fuchs, S. Fizek, P. Ruffino, and N. Schrape, Eds. LÃijneburg, Germany: LÃijneburg: meson press 2014, 06 2014, pp. 305-331.

[67] J. Geuens, L. Geurts, K. Gerling, R. De Croon, and V. Vanden Abeele, "Dyadic lenses for the motivational design of mhealth: Bridging the gap between health theory and app design," in 2019 IEEE International Conference on Healthcare Informatics (ICHI). IEEE, 2019.

[68] T. Sonne, J. Müller, P. Marshall, C. Obel, and K. Grønbæk, "Changing Family Practices with Assistive Technology," in Proceedings of the 2016 CHI Conference on Human Factors in Computing Systems - CHI '16. New York, New York, USA: ACM Press, 2016, pp. 152-164. 